Governing adaptation across scales: Hotspots and hesitancy in Pacific Northwest forests

Shannon M. Hagerman

Department of Forest Resources Management, University of British Columbia 2031-2424 Main Mall, Vancouver British Columbia Canada V6T 1 Z4

Phone: +1 606-827-2625

Email: Shannon.Hagerman@ubc.ca 


\section{Governing adaptation across scales: Hotspots and hesitancy in Pacific Northwest forests}

Climate change is one of the greatest challenges to sustainable management of forests and grasslands and to human well-being that we have ever faced, because rates of change will likely exceed many ecosystems capabilities to naturally adapt. Without fully integrating consideration of climate change impacts into planning and actions, the Forest Service can no longer fulfill its mission (Forest Service Strategic Framework for Responding to Climate Change, October 2008).

\section{Introduction}

In 2008, the United States Forest Service (USFS) declared that its ability to fulfill the agency's mission of sustaining "the health, diversity and productivity of the Nation's forest and grasslands to meet the needs of present and future generations" was at risk due to the impacts of climate change (USFS-USDA, 2008). This statement conveys concern that the societal and ecological benefits derived from the 193 million acres of publicly owned forests in the US may not be viable in the future given projected changes in temperature, precipitation and disturbance regimes (IPCC, 2014). In effort to secure the ongoing delivery of their respective missions, the USFS, alongside other federal resource management agencies have responded by developing an array of institutional responses to support adaptation to expected climate impacts (Table 1). The projected biophysical impacts of climate change interacting with these policy responses are together poised to reconfigure resource management systems in terms of the objectives sought, means taken and knowledge relied upon.

This article examines the expression of federal-level initiatives as they are implemented within sub-regional contexts. While there exists a rich conceptual literature offering prescriptive insights for developing climate adaptive responses in resource management contexts, relatively few empirical studies have examined how managers and specialists are engaging with and implementing climate adaptation policies and plans in practice. With almost a decade of climate adaptation initiatives now written in federal legislation, policy and strategic plans (Bierbaum et al., 2013) it is timely to examine how federal policy directives are modified, contested and transformed by managers and specialists working at sub-regional levels. 
The central objective of this paper is to deepen understanding about the range of factors currently shaping efforts to adapt to climate change in sub-regional resource management contexts. Based on in-depth interviews and a close reading of policy and planning documents explored through a case study within the Pacific Northwest Region (PNW) of the USFS, the argument advanced in this article is that the importance of material factors such as technical information, while important, have been overemphasized as barriers to adaptation relative to the roles of nonmaterial factors including attitudes and trust.

\section{Conceptual background}

Decades of scholarship concerned with the interrelationships between humans and the nonhuman environment illustrate that individuals, institutions and societies continually adapt to multiple forms of environmental and social change through time and across scales (Adger et al. 2005). The term adaptation itself varies greatly in usage. Ecological anthropologists refer to social adaptability (both cultural and behavioral) in response to changing environmental and social conditions (Moran 2006), institutional and adaptive governance scholars highlight institutional flexibility and organizational adaptation in response to multiple interacting economic, cultural, socio-political and biophysical conditions (Folke et al. 2005), and evolutionary biologists and geneticists describe biological adaptation to changing environmental conditions created by human activities. More, within the problem-defined field of climate change, adaptation refers to adjustments in "social-ecological systems in response to actual and expected impacts of climate change in the context of interacting nonclimatic changes" (Moser and Ekstrom 2010).

While the latter domain of climate change adaptation has emerged as a field of inquiry in its own right, the social processes that shape adaptation to climate change (and other drivers) in different organizational contexts - such as the USFS - is more fully understood through the lens of institutional adaptation and organizational behavior. Accordingly, the work presented here draws from behavioral and institutional theories of organizational adaptation as applied to concerns relating to climate change adaptation in natural resources management. The latter specialist literature on climate change adaptation in natural resource management settings provides the 
policy and problem context for identifying key themes and debates unfolding in that applied research domain. The following sections describe insights from these related strands of inquiry with an emphasis on drawing the linkages between insights relating to human behavior, institutions and organizational change broadly, and the concept of "barriers" in the specialist adaptation literature.

\section{Institutional adaptation and human behaviour}

Social scientists working from multiple disciplines have long been concerned with how individuals, communities and sectors adapt to a wide range of changing conditions (including but not limited to climate change) (Smit and Wandel, 2006). The study presented here seeks to develop an understanding of the social processes through which the need for institutional adaptation (in terms of changes to management practices and policies) is perceived by individuals, pursued through management actions, and the factors that shape these responses within organizations. This intention implicates scholarship that inherently if not explicitly examines the "barriers" that shape and constrain adaptation in organizational contexts such as the USFS. Following the classification of Berkhout (2012), this paper draws insights from institutional and human behvioural perspectives on organizational adaptation. Research in the behavioral strand of this literature highlights how individual attitudes and perceptions of risk (Grothmann and Patt, 2005) including the role of heuristics and biases (Kahneman, 2011) contribute to shaping patterns of behavior. Research in the institutional strand emphasizes how these behavioral dimensions interact with social relationships, including informal ones (Pelling et al., 2008) and broader social-political economic contexts and policies (Matthews and Sydneysmith, 2010) to shape the extent and form of adaptation (Berkhout, 2012).

Similarly, many scholars studying adaptation in the climate-related domain assert that climate adaptation implementation is at its core a "governance issue" (Adger et al. 2009). Reflecting an understanding of governance that implicates interactions between knowledge, human behavior and institutions (Lemos and Agrawal 2006), studies concerned with governance-related aspects of climate change adaptation have demonstrated the role of individual attitudes and values (Ekstrom and Moser, 2013; Hagerman and Satterfield, 2013), perceptions of risk (Spence et al., 
2011), and leadership (Folke et al., 2005) of individuals as they operate through formal and informal institutions (Agrawal, 2010; Lemos and Agrawal, 2006), mediated by social relationships including trust (Adger, 2014; Folke et al., 2005, Pelling and High 2005) within the bounds of specific policy interventions, and in the context of broader social-political forces (Staudt et al., 2013; Suckall et al., 2014). Adopting the language of organizational adaptation scholars, some of these factors can be described as endogenous to the organization, system or community in question (e.g. attitudes, perceptions of risk) and some as exogenous (markets, economic context, structural relationships across agencies, broader political and institutional arrangements) (Berkhout, 2012).

The perspectives outlined above serve as the analytical foundations for this research. The specialist literature on climate adaptation in natural resource management contexts provides additional context in terms of identifying emerging trends and key debates as they pertain to active discussions for advancing climate change adaptation in natural resources management policy and planning. Foundational scholarship at the nexus of climate change adaptation and natural resources management focused on establishing the basis for adaptation by linking expected climate impacts to potential adaptation options (Joyce et al. 2008, Baron et al. 2008); developing the logic for vulnerability assessments (Furniss et al., 2013; Halofsky et al., 2011) and designing frameworks to guide decision processes for developing adaptation strategies (Millar et al., 2007; Ogden and Innes, 2009; Peterson et al., 2011). After decades of synthetic and prescriptive work, climate adaptation scholars working within this field are increasingly turning their attention to identifying and addressing challenges of adaptation implementation. These challenges are commonly examined through the concept of barriers (Eisenack et al., 2014; Jantarasami et al., 2010; Moser and Boykoff, 2013; Moser and Ekstrom, 2010).

Different approaches to categorizing and understanding barriers to adaptation abound in the climate change adaptation literature (Biesbroek et al., 2013; Eisenack et al., 2014), although recurrent distinctions include institutional, informational and human behavioral categories. Of these, there has been a tendency in both scholarly and policy domains to focus a tremendous amount of attention on addressing the role of technical information as a presumed barrier to adaptation. As one example, the US Government Accountability Office highlights the need for 
more information about climate impacts to inform responses (GAO 2009). Echoing these concerns, climate adaptation scholars have developed diagnostic conceptual frameworks designed to enhance the linkages between adaptation science and decision-making (Moser and Ekstrom, 2010). Others have examined perceptions of information as a barrier to adaptation (Archie et al., 2014; Jantarasami et al., 2010; Tribbia and Moser, 2008), and many of these same studies report lack of information as the most frequently cited barrier to adaptation by land managers themselves (Archie et al., 2014, 2012, Jantarasami et al. 2010).

The analytical and applied perspectives outlined above paint a complex, but behaviorally and institutionally realistic portrait of the suite of interacting factors that shape adaptation. This paper leverages these insights to develop a framework for conceptualizing barriers that builds on common categories in the specialist climate adaptation literature, and that also seeks to account for the interplay between behavioral and institutional aspects of adaptation. The core categories of barriers as seen in the specialist adaptation literature are retained and used here, but developed further by locating them along two dimensions: institutional origins and materiality. Institutional origins distinguish between those barriers that originate within the USFS (endogenous barriers) and those that originate external to the USFS (exogenous barriers). Materiality distinguishes between concrete, material barriers (such as financial and human capacity, technical information, regulation and jurisdiction) and intangible nonmaterial barriers related to human behavior (such as attitudes, experience, trust and credibility). To some extent the divisions between these categories are arbitrary considering the interrelationships and feedbacks between them. Acknowledging this, the categories are retained and used here for analytical purposes.

Informed by the discussion above, the research presented here examines the roles of human behavioural (e.g. attitudes and trust), institutional (e.g. capacity, regulatory obligations, agency objectives, jurisdictional purview) and technical (informational) factors in shaping responses to federal adaptation directives at sub-regional scales. The following questions guided this research: How do managers working at sub-regional scales view the challenge of adaptation in the context of their work? How do these views interact with institutional factors to shape engagement with federal agency directives? 
The intentions of this work are both pragmatic and analytical. Pragmatically, this case provides insight into the specific challenges that managers face (and the actions that they take to overcome challenges) as they seek to implement federal adaptation policy directives at the subregional forest level. Identifying the context-specific factors that enable and constrain change in particular locales provides an opportunity to explore policy options to facilitate adaptation in practical terms. Analytically, this work brings insights from the literature on human behavior and institutional adaptation to provide deeper understanding about the societal aspects shaping barriers to adaptation in natural resources management contexts.

\section{Adaptation and aquatic ecosystems in the Pacific Northwest Region of the USFS}

The research presented here is part of a broader project on adaptation decision making for aquatic ecosystems on forestlands across the Pacific Northwest Region (PNW) of the USFS. The PNW is one of 9 management regions within the USFS. The PNW region covers 24, 641, 010 acres (USFS-USDA, 2012) and is located in the north Pacific coast region of the United States. The PNW region includes 17 National Forests across the states of Washington $(n=6)$ and Oregon $(n=11)$. From fisheries, to aquatic organisms, to infrastructure including roads, and water supply, many if not all of the values managed for on forests lands occur at the nexus of forests and water. Moreover, these values are known to be sensitive to the anticipated impacts of

climate change (Vose et al., 2012). Forest managers and specialists working at the regional and sub-regional forest level will play a crucial role in navigating these changes through their management priorities and actions. 
Table 1. Examples of some federal-level adaptation-related initiatives within the US Forest Service.

\begin{tabular}{|c|c|c|}
\hline Date initiated & Adaptation Action and Description & Reference \\
\hline 2008 & $\begin{array}{l}\text { Forest Service Strategic Framework for Responding to } \\
\text { Climate Change }\end{array}$ & (USFS-USDA, 2008) \\
\hline 2008 & $\begin{array}{l}\text { Climate Change Resource Center | Connecting land mangers } \\
\text { and decision makers with usable science }\end{array}$ & $\begin{array}{l}\text { http://www.fs.usda.gov/ } \\
\underline{\text { ccrc/ }}\end{array}$ \\
\hline 2010 & $\begin{array}{l}\text { USDA Strategic Plan FY 2010-2015 | Strategic Goal 2: } \\
\text { "Ensure our national forests and private working lands are } \\
\text { conserved, restored and made more resilient to climate } \\
\text { change while enhancing our water resources" }\end{array}$ & (USDA, 2010) \\
\hline 2010 & $\begin{array}{l}\text { Office of the Climate Change Advisor, and associated } \\
\text { Regional and Unit level Climate Change Coordinators }\end{array}$ & N/A \\
\hline 2010 & $\begin{array}{l}\text { National Roadmap for Responding to Climate Change | } \\
\text { Describes the Climate Change Performance Scorecard as a } \\
\text { key part of the Forest Service response to Objective } 2 \\
\text { outlined in the USDA Strategic Plan FY 201-2015 (above) }\end{array}$ & (USFS-USDA, 2010) \\
\hline 2011 & $\begin{array}{l}\text { Navigating the Climate Change Performance Scorecard | } \\
\text { Compliance standards and guidance }\end{array}$ & (USFS-USDA, 2011) \\
\hline 2014 & USDA Climate Change Adaptation Plan & (USDA, 2014) \\
\hline 2012 & $\begin{array}{l}\text { National Climate Assessment Forest Sector Technical } \\
\text { Report }\end{array}$ & (Vose et al., 2012) \\
\hline 2014 & $\begin{array}{l}\text { USDA Regional Hubs for Risk Adaptation and Mitigation to } \\
\text { Climate Change | Co-production of knowledge }\end{array}$ & (USDA, 2015) \\
\hline
\end{tabular}




\section{Methods}

\section{Approach, data collection and analysis}

To explore the views of managers about climate change risks and perceived barriers to adaptation, a single descriptive case-study approach was used (Yin, 2003). The primary method of data collection was in-depth semi-structured interviews (Holstein and Gubrium, 1995). This method was chosen over survey methodology due to the initial stage of research inquiry, and the research objective of gaining an in-depth understanding of the experiences and views of respondents (e.g. Charmaz 2006). Interview data was supplemented with a detailed reading of secondary sources obtained from policy documents, reports, and organizational literature. Empirical insights are drawn from these combined data sources.

Interviews with 25 forest managers and specialists working within the PNW region were conducted in 2012. This study employed a purposeful sampling strategy (Creswell, 2013). Participants were selected based on their expertise relating to aquatic ecosystem management (specifically fish biologists, hydrologists and regulatory specialists). Variation across respondents was deliberately sought according to sub-regional locale, institutional setting and gender (Table 2). Participants were identified in consultation with (and with permission from) USFS collaborators, in combination with a review of adaptation initiatives and associated key personnel in this region, and from respondents themselves who sometimes recommended key people to speak with.

With a few exceptions, interviews were conducted in person at the participant's place of work. Interviews ranged in duration from 40 - 90 minutes. Following a set of general questions about the participant's expertise and job description, respondents were asked about the systems that they manage/study in terms of key aquatic values of concern, drivers of change (including but not limited to climate change), information needs, options for adaptation and management, institutional rules and governance and perceived barriers and opportunities. Appendix A provides an overview of the types of questions explored with participants. All interviews were audio- 
recorded, transcribed verbatim and analysed within qualitative data analysis software (HyperRESEARCH for Mac 3.0).

Analysis involved line-by-line coding to develop initial codes followed by more focused coding to identify emergent themes (Charmaz, 2006). The cyclical and iterative coding process allows the researcher to continuously reflect upon and explore the themes identified in the data, and the relation of these emergent themes to those that originally structured and framed the study (Emerson et al., 1995; Saldana, 2013). Following established protocols for systematically collecting and analysing qualitative data in the research tradition of grounded theory (Charmaz, 2006), this inquiry began with an interest in information needs, perceived barriers and opportunities (as indicated above and as derived from the literature). These concepts acted as "points of departure" (Charmaz, 2006) that informed the design of the interview schedule and structured analytical thinking. Additional themes/concepts also came to include those (emergent) topics and themes that respondents themselves defined as important and that were identified through the process of open coding. Thus, in contrast to a deductive model of quantitative research, the original concepts provide an initial, tentative and partial analytical footing for conducting the research that was expanded and revised throughout the research process. Interview data was supplemented with an extensive reading of policy and internal agency documents relating to adaptation on federal forest lands. This reading informed the types of questions that were asked, and helped to place the research findings in broader context.

Following the protocols for establishing "credibility" or "confirmability" in qualitative research, this study used a combination of strategies to consider and evaluate alternative interpretations (Maxwell, 2013) and achieve a "confluence of evidence" (Eisner 1991, cited in Creswell 2013, p: 246). These strategies included continuous reflection through the research process (to identify and understand potential researcher bias), ongoing arms-length observation as an independent scientific researcher through (over a period of 4 years), triangulation of data sources (primary and secondary sources), and peer debriefing (to validate responses through presenting the findings at practitioner meetings). The author conducted all interviews as well as the coding and analysis. This research was approved by the University of Washington Institutional Review Board, Human Subjects Division. 
Table 2. Descriptive characteristics of participants.

\begin{tabular}{|c|c|c|c|c|c|c|}
\hline & \multicolumn{5}{|c|}{ Total Sample: $\mathrm{N}=25$} & \multirow[b]{3}{*}{$\begin{array}{l}\text { Climate } \\
\text { Coordinator }\end{array}$} \\
\hline & \multicolumn{5}{|c|}{ Expertise domain } & \\
\hline & Hydrologist & Fish Biologist & Other * & Regulatory & Totals & \\
\hline \multicolumn{7}{|l|}{ Sub-regional setting } \\
\hline West-side National Forest & 4 & 2 & 3 & 1 & 10 & 5 \\
\hline East-side National Forest & 4 & 3 & - & - & 7 & 2 \\
\hline Regional Office & 1 & 1 & 1 & 2 & 5 & 1 \\
\hline Research Station & 1 & 2 & - & - & 3 & \\
\hline Totals & 10 & 8 & 4 & 3 & 25 & 8 \\
\hline \multicolumn{7}{|l|}{ Gender } \\
\hline Male & 7 & 6 & - & - & 13 & 1 \\
\hline Female & 3 & 2 & 4 & 3 & 12 & 7 \\
\hline Totals & 10 & 8 & 4 & 3 & 25 & 8 \\
\hline
\end{tabular}

* Genetics, soils, ecosystems

\section{Results}

The empirical evidence obtained through interviews is organized and presented below according to 4 central themes identified through the analysis. These themes are: 1) a spectrum of climate adaptation engagement across the region 2) endogenous barriers (and non-barriers) of adaptation engagement including mistrust and the production of knowledge 3) exogenous barriers including regulatory obligations, policy uncertainties and jurisdictional purview and 4) preferred adaptation pathways and anticipated future dilemmas.

\section{A spectrum of climate adaptation engagement across the region}

USFS employees across the PNW region are highly regarded for their contributions towards advancing the science and practice of adaptation. Forest service individuals have played pivotal 
leadership roles in a range of regional-wide adaptation initiatives (e.g. North Cascadia Adaptation Partnership, Olympic Case Study and Watershed Vulnerability Assessments) and are recognized regional leaders with the forest service. At the same time, interviews with managers across the region revealed considerable variation in the degree of sub-regional engagement with adaptation. This variation ranged from proactive and concrete adaptation responses in some units, to cautious awareness, to dismissal and thin engagement in others.

Many interviewees anticipated this variation.

I think this national forest is pretty far ahead in our thinking about climate change. I'll be curious if you find hot and cold spots in terms of people thinking about climate change. My sense is on some forests, there is an individual that is really concerned and thinking about climate change. And then you go to the next forest, and it is like: "Oh no, we can't keep our head above water, period." I think it varies a lot. [12]

A few national forests across the region exemplify the proactive end of this spectrum. What these national forests share in common is the presence of individuals who are personally concerned about the impacts of climate change. These individuals express positive attitudes towards engaging with and advancing adaptation within their programs of work in spite of potentially overwhelming, competing work obligations. One manager, described members of their team working on an adaptation project as follows:

We are all just really motivated. All of us are regular program managers-we have full-time jobs - but we found the space to do this [climate adaptation work] because we were interested. [21]

Interviewees often underscored the importance of the attitudes of individuals in leadership positions in particular.

We have a new staff officer who's very interested in climate change. My last boss would say, "Why would that be a priority? Don't do that." It's very variable. Not just at a forest level, but at the district level. It depends on the ranger. It depends on the forest supervisor. It depends on your staff officers. [16]

At the opposite end of the engagement spectrum, individuals on other national forests expressed a greater sense of reluctance towards addressing climate change in their programs of work. 
There are probably other forests that have embraced it [adapting to climate change] more wholeheartedly within their agenda. We've got a climate change coordinator, but [their] impression in terms of interfacing with the forest leadership team is that there's not a lot of...well, willingness to bring on climate change as a major issue that we need to be addressing. [20]

Individuals who described thin levels of engagement on their unit commonly invoked issues of workload and capacity.

It [addressing climate change] was never a priority for our leadership team. 'Cause we had so much stuff to do, our... all of our supervisors said we're just going to put it on the backburner. It was never made a priority for funding, or time. [2]

In contrast, others discussed ways in which they and their colleagues found ways to implement adaptation initiatives in spite of pervasive capacity shortfalls.

There are people who have been in the agency long enough to know that if you want to do something, go ahead and just work it into your regular program of work. That's where things get going. There shouldn't be a barrier if you're not funded. [17]

In between the adaptation-engaged forests and the adaptation-reluctant forests, lie units whose response can best be characterized as cautiously aware.

We've been quite active in putting on workshops and thinking about climate change and where we're headed as a forest. We also tend not to be alarmist. We think about the projects that we're doing, and we think okay... what we're doing now is fairly good to be able to be resilient for climate change. [18]

Managers such as the respondent above were engaged in capacity building climate activities, and described climate change as an important concern. At the same time, they expressed faith in their current management and remain "reluctant to make bold changes in terms of how we manage things." [16]

\section{Endogenous barriers (and non-barriers) of adaptation engagement across the PNW}

Respondents directly and indirectly discussed a suite of factors (barriers) that influence their engagement with adaptation implementation. Some factors were anticipated and observed as 
influential (e.g. human and financial capacity). Other factors were anticipated based on the literature, but not observed as influential in this case (e.g. technical information). Still other factors less commonly discussed in the literature emerged as prominent factors in this context (e.g. attitudes, trust and experience). Figure 1. summarizes the barriers discussed by managers as organized along the institutional origins and materiality dimensions described above. This conceptual device provides the organizing framework for presenting and interpreting the empirical data.

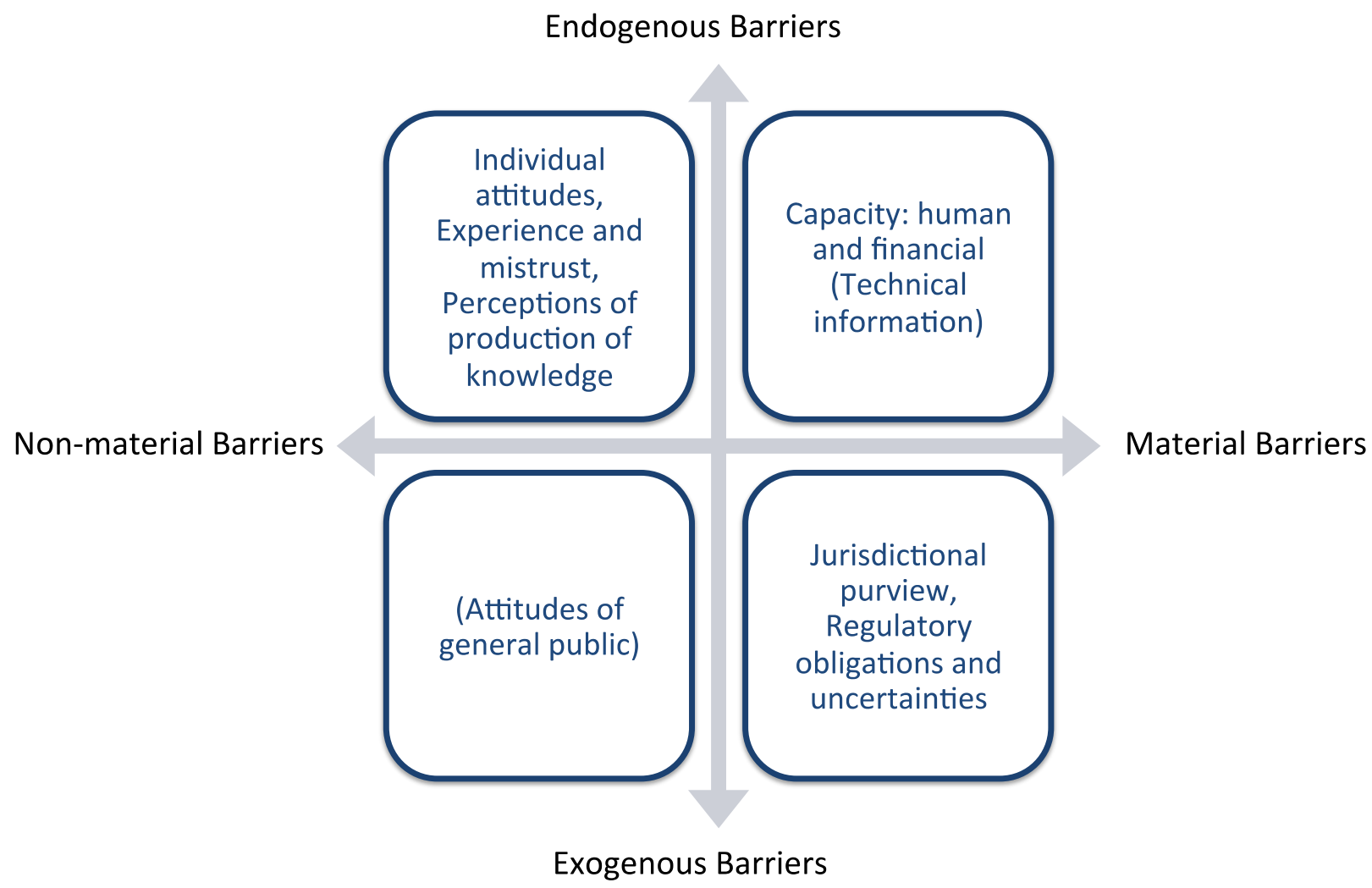

Fig 1. Barriers to adaptation as perceived by managers organized by institutional origins and materiality. Barriers in parentheses were not viewed by respondents as currently influential in shaping adaptation implementation

Capacity: unfunded mandates $v$. institutionalized targets 
Respondents working within units at the adaptation-reluctant end of the engagement spectrum commonly explained the lack of engagement at the national forest level in relation to the barriers that prevent them from meaningful action. Not surprisingly, many managers identified the lack of financial resources as the most influential barrier. This was often discussed in relation to a longer list of pressing intra-institutional budget-driven priorities that did not include climate change. Across the region, managers referred to action on climate change as an "add-on responsibility" [25] and one of many "unfunded mandates." [13]

Direction needs to come with money. Do you know the term unfunded mandate? You're not going to get very far if you tell us to go do something without money. It's then when I say, "What do you expect us to do?" I mean, money: that's how Congress tells us what to do. [13]

Managers often highlighted that what does drive decision-making on national forests are budgetdriven targets (e.g. board feet, miles of stream restored).

What drives the Forest Service and what drives this forest is not climate change, but targets that have to do with timber, or range. Until you actually can force that change on the national level, I think it becomes more difficult to engage in why climate change is important. [23]

Because we don't have a target [for climate adaptation] and because it's not budget driven, we just bring it onto the plate half an hour before we have to get it done. [2]

In addition to financial barriers, a lack of human resources was consistently identified as a problem across the region. Many interviewees lamented the reality of an aging and shrinking workforce and the resultant erosion of expertise and human capital.

It's going to be a real problem, this wave of retirements...we had a very large research organization... at least here in the Pacific Northwest. When I came here, every office in this building was stuffed with people. And now you can walk down the hallway and think, where is everybody? [15]

Experience and (mis-) trust in the stability of the mandate 
Other respondents described a measure of caution, and in some cases mistrust towards engaging with adaptation initiatives given their experience with previous agendas.

We went from "You can't talk about climate change" to "We have to talk about it, but you don't have to say a whole lot," to "We need all of the possible details that you can come up with!" What the planners and the regional office think is important has constantly changed over the last six or eight years: from denial, to the biggest issue that's out there. [24]

Having seen unfunded mandates - like responding to climate change - come and go over time, some managers regard expectations associated with related initiatives with a large measure of caution and hesitancy. Indeed, in the absence of personally motivated individuals and resultant pro-adaptation culture at the unit level, issues of capacity, missing institutional incentives and lack of trust can all combine for relatively thin engagement with agency-level climate adaptation initiatives. The most concrete expression of this reluctance centered on the Forest Service Performance Scorecard for Implementing the Forest Service Climate Change Strategy. The Scorecard is the formal institutional link between Objective 2.2 of the USDA Strategic Plan (USDA, 2010) and the regional/sub-regional administrative units (e.g. individual national forests). The Scorecard consists of 10 yes or no questions across four dimensions: Organizational Capacity, Partnerships \& Engagement, Adaptation, and Mitigation. Each National Forest must achieve 7/10 elements to be in compliance. Regions, Research Stations and national programs will also be required to show evidence "of contributions to accomplishment on scorecard elements" (USFS-USDA, 2010).

For the purposes of this study, the two most relevant elements of the scorecard are Elements 6 and 7 within the Adaptation dimension. Element 6 asks if the unit has "engaged in developing relevant information about the vulnerability of key resources...to the impacts of climate change". Element 7 asks whether or not the unit in question "conducts management actions that reduce the vulnerability of resources and places to climate change" (USFS-USDA, 2011). Although "few if any forests" are expected to be in compliance initially, the national target is $100 \%$ compliance by 2015 (USFS-USDA, 2011). According to the October 2014 newsletter of the Climate Change Advisor's Office (USFS, 2014), 74 of 113 (65\%) administrative units across all regions report achieving $7 / 10$ elements. Approximately $75 \%$ of units report achieving compliance for Assessing 
Vulnerability (Element 6), up from 20\% compliance in 2011. Similarly, just over $75 \%$ of units across the agency report achieving compliance for Adaptation Actions (Element 7), which is up from approximately $45 \%$ in 2011.

Responses from managers revealed a range of perspectives with respect to the Scorecard.

I threw in my two cents on some things, but it wasn't anything. The scorecard...it's a moot program. We get emails every once in awhile, but it's not really a part of our program. [20]

This statement illustrates a relatively tempered example of amongst numerous and much more frustrated responses (data not presented). However, not all respondents viewed the scorecard as irrelevant program. A minority few saw it as a viable opportunity to facilitate change.

I was in a meeting last month and the conversation evolved from the scorecard being something that we have to do to try and look good...take things that we're doing, write them down, and try and puff ourselves up, towards a perception of the scorecard actually doing something in response to climate change. I think the scorecard is actually a good tool. So, it really is cheating yourself to just do it as a bean-counting exercise [4]

\section{Information, autonomy and the production of knowledge}

Contrary to the often-presumed importance of technical information as an adaptation barrier, mangers interviewed for this study did not view a lack of information as a barrier to adaptation in the PNW region. Certainly, some respondents noted that some specific products (mapping vegetation transitions, spatial identification of sensitive headwaters) would be of "great assistance" [16]. Much more commonly, managers report feeling overwhelmed by an abundance of information: “There's a lot of information available. For me personally-much more information than I need.” [16] Moreover, managers expressed a strong interest in moving ahead with adaptation using the information they already have.

We have a lot of research. We have a lot of documents. But I still don't have the sense of what it means to my bottom line, and to our staff area's bottom line. How do we take all that existing information and have a resource specialist get to work based on informed recommendations for future management. [2] 
Conversations about the adequacy and usability of information to support adaptation often turned quickly from discussions about the existence of knowledge itself, to its production. One manager described the approach of their forest as follows:

I think eventually when we start to see more of the results, and start to look at some of the assessments, and write some of our own adaptation strategies, and really start to think about how we put this on the ground, that's when we'll start saying maybe we should start doing our priorities based on what we know will change, or we think will change. [18]

These conservations reveal the complex relationship between unit-level identity and participation in the production of knowledge that would be seen as legitimate, credible and ultimately usable. Other managers expressed similar sentiments regarding the importance of local knowledge and closely related issues of participation. In the following example, a manager recounted a recent climate change assessment effort that originated external to their forest.

So [Institution/agency X] came out and did some climate analysis and presentations. And the local folks here were like, "yeah, yeah...we know that. We live here. We understand our agricultural systems. We understand our water supply systems." [21]

In a related vein, another manager raised the crucial issue of participation as it relates to the production of knowledge.

There was a two-day symposium last year presenting the latest science. And we weren't invited. I'm not trying to complain and say well, "we should be invited". But, I know some of the forests like ours were not invited, and a lot of people have expressed interest. [16]

\section{Exogenous barriers: Regulatory obligations, uncertainties and jurisdictional purview}

Respondents also discussed the importance of inter-agency barriers such as regulatory obligations and limits to management purview in shaping engagement with adaptation directives coming from the federal office. Many managers argue that an all-encompassing focus on meeting existing legal requirements (e.g. National Environmental Policy Act; NEPA, Clean Water Act; CWA) tends to swamp any potential to consider options beyond that which is legally required. 
Because we spend so much time trying to make sure that we're meeting our [federal] legal requirements and meeting all state laws as well—climate change takes a back seat. It's like yeah, we'll deal with that when we're ensuring that we're meeting all these other things that we are legally mandated to do right now. [3]

Here again, the threads of hesitancy and mistrust about the stability of the climate adaptation mandate are revealed. Many respondents linked a reluctance to act on climate change to deep uncertainties about how regulators will respond to climate change in the broader social-political context. Conversations about these regulatory uncertainties centered primarily on NEPA.

The way that we do NEPA has come about through a series of lawsuits essentially. And so.... there's a bit of a reluctance to say okay, well let's throw in this climate change thing, see how it shakes out. [4]

Others noted the relatively limited reach of management activities in influencing the land base and the fact that activities in the lower reaches of rivers and estuaries on private and agricultural land "could be a total driver of fish populations to the point that it really doesn't matter what our forest management is." [1]

\section{Preferred adaptation pathways and anticipated future dilemmas}

In the context of multiple and immediately pressing drivers as described above, all respondents advocated mainstreaming as the preferred approach for adaptation both on philosophical grounds (it makes logical sense) and practical grounds (it is what is possible).

At least from aquatic's perspective-[mainstreaming] is what you have to do. Addressing climate is not a special, stand-alone thing. The way that it succeeds is incorporating it into everything that you do. [6]

Others argued that given an overwhelming collection of existing initiatives and demands and the fact that climate remains an unfunded mandate, mainstreaming in the sense of integrating climate into existing frameworks is the most practical approach 
Things are just so tight with time, people, and money, that we're going to end up having to piggyback on existing things: the Watershed Condition Framework, the Terrestrial Condition Framework that's supposed to be coming down. These things that get handed down from the Washington or regional offices, I think that's how we're going to have to get things done is to integrate climate within these existing requirements. [4]

Further, managers are fatigued and exasperated by the prevalence of what they perceive as overly general guidance that advocates what they are doing already.

The [recent adaptation publication] was interesting. I think a lot of people thought well, you know this is really great and out front. But, if you delve into it, there's not a lot of specifics in there. It is still the mom-and-apple-pie phase of the game. Really getting down to what should we do in this river basin? We're a ways away from having any kind of consensus on that. [12]

Despite an overriding sense that current management actions are sufficient to respond to climate change, managers anticipate that the prioritization of their work (spatially and temporally) will be one aspect of decision making that will ultimately diverge substantially from the status quo. A number of respondents used the example of Bull Trout (Salvelinus confluentus) to illustrate this perspective. Bull trout are native cold-water specialists that occupy streams throughout the PNW region. Bull Trout are currently listed as Threatened under the US Endangered Species Act.

Bull Trout is pretty much on the edge of its range here. And so it's possible that we may have to make some hard decisions about conservation in places where they're not likely to persist. How much energy do we put into restoring connectivity or function in places where they're not going to stay? And I don't know how we do it in the current regulatory world given listed species. [21]

At the same time, these conversations reflect the humility of managers across the regional and an ongoing dedication to conservation objectives.

Some people say, "forget Bull Trout. They're not going to survive." But is there something we should be doing for Bull Trout? And what is that? Nobody has written off any species. We are in no position to do that. And we should be humble and do everything we can. [13]

Some interviewees anticipated the importance of experiential drivers as triggers of more substantive action on difficult decisions such as those described above. 
There's some hard decisions that we have to make, and I don't think we're quite ready to make them. And it may take extended drought...it may take calamity to make those changes. [21]

Another manager expressed a similar intuitive theory about the role of experience in motivating adaptation and policy change more broadly.

People forget. I knew people would, but I...I hear it already. It's like oh, that culvert, it'll last a long while. It'll last longer. Oh, it's not quite big enough? And I'm thinking, "It's been too long since we had our last flood. We need a new flood." [17]

\section{Discussion}

The overall objective of this study was to characterize the views of USFS managers and specialists in the PNW about adaptation implementation and in so doing, to identify the factors currently shaping adaptation at the sub-regional level. Consistent with the findings of other recent case studies (Archie et al., 2012; Ekstrom and Moser, 2013; Jantarasami et al., 2010; Tribbia and Moser, 2008), managers in the PNW identify a suite of commonly reported barriers to adaptation that can be categorized as material. These include capacity (financial and human), lack of institutional commitments, and regulatory constraints and uncertainty. More compelling, are observations from this study that illustrate the prominent and interrelated roles of nonmaterial factors including attitudes, experience, and trust in shaping engagement with adaptation across the region. Further, contrary to prevailing assumptions about the presumed importance of information, this study found that technical information was not perceived by managers as a barrier to adaptation. More, discussions about information and knowledge reveal important insights into the social processes by which knowledge is created and perceived as legitimate and credible. Three policy-relevant topics arise for discussion in the context of understanding the implications of these observations for adaptation.

\section{Correlates of engagement and the importance of nonmaterial factors}

Results of this study reveal that variation in the degree of engagement with agency-level adaptation implementation across the region was tightly coupled with the attitudes of individuals 
in leadership positions at the unit (national forest) level. This observation sits in contrast with a recent study of US land managers including the USFS that concluded that attitudes about climate change do not influence responses to adaptation (Archie et al. 2013). In the study presented here, managers themselves viewed the attitudes of key individuals as being crucial for overcoming persistent material barriers including a lack of capacity and institutional incentives. Proadaptation attitudes were seen by managers to create a culture of engagement that directly influenced the advancement of adaptation-related programs of work, irrespective of capacity or institutional incentives. This interpretation is consistent with conclusions made by Ekstrom and Moser (2013 and 2014) who similarly emphasize the connection between the values of individuals in leadership positions as being especially influential for shaping adaptation outcomes. More broadly, this underscores the importance and transformative potential of leadership to overcome pervasive inter-institutional barriers (Folke et al., 2005). This observation also reflects longstanding insights at the nexus of values, power and policy where political ecologists and other environmental social sciences and humanities scholars have long underscored that whose values are pursued matters tremendously in shaping policy outcomes (Adger et al., 2009; Castree et al., 2014).

\section{Understanding the "information barrier:" Knowledge production rather than provision}

A second topic that arises from the empirical observations presented above concerns the presumed and observed importance of information, and the social processes by which information comes to matter. Despite prevailing assumptions about the primary role of information as a barrier to climate change adaptation, this study found very little evidence to support these assertions. Analysis of the data presented here suggests that not only was technical information not regarded as a barrier to adaptation, managers often noted that they had too much information to make sense of. Managers expressed significant guidebook and guidance fatigue towards an abundance of recommendations that fail to connect expected climate impacts with their day-to-day decision-making. In part, this observation can be understood in the context of the stage of the adaptation decision-making process (Moser and Ekstrom, 2010) that characterizes current adaptation initiatives across the PNW. Indeed, a tremendous amount of climate impacts research and knowledge has already been generated for this region. As 
adaptation initiatives increasingly extend beyond the "understanding phase" and into the "planning and management phases" (Moser and Ekstrom, 2010) one might anticipate perceptions of the importance of information as a barrier to wane. Alternatively, as adaptation plans are implemented in specific locales, the need for location-specific information may increase. Irrespective of these potential dynamics and intersections, given the relative volume of academic and policy conversations about the presumed and prevailing importance of information as a key barrier/ingredient for adaptation, the observation that information was not currently perceived as a barrier to adaptation in this context is an important finding in its own right.

More noteworthy, is what conversations about information reveal about the production of knowledge, rather than its availability. Specifically, managers across the region expressed a strong sense of autonomy in the production of local knowledge at the unit-level. Managers spoke about the perceived imposition of outsiders who purport to hold the best knowledge about the systems for which managers themselves have extensive local knowledge about. Consistent with the literature on the co-production of knowledge, credibility and trust (Jasanoff, 2004), this observation underscores the importance of meaningful participation across institutional levels from the beginning of any assessment, adaptation or synthesis project. A common informationrelated prescription found in the adaptation barriers literature is the call for further research that focuses on creating science that is not only available for decision-making but also usable for decision making (Archie et al., 2012). A focus on usability is a reasonable and important aspect of an applied response and research agenda. Equally important are initiatives and research that pay attention to the production of knowledge rather than its provision. A focus on the former would help attend to issues of participation such as raised by respondents in this study, and enhance the likelihood of generating knowledge that is locally informed and seen as credible in the eyes of users. Some practitioners have suggested that initiatives such as the Regional Integrated Sciences and Assessments (RISA) program demonstrate some promise towards achieving this.

\section{Policies past and future}


Third, the empirical material indicates a complex relationship between individual experience, history and trust in shaping current engagement with adaptation initiatives. Some individuals who have worked with the forest service for decades or longer expressed hesitancy and latent mistrust towards the stability of the climate-mandate given the wide swings in priorities that they have witnessed over time. On the one hand, managers and specialists who are personally motivated, tend to find ways - within the bounds of institutional guardrails and the capacity of the forest - to implement adaptation initiatives. By contrast, those who hold ambivalent or more dismissive views about climate change are unlikely to engage in anything more than is minimally required. For this latter group, only formal, budget-driven targets are likely to drive pro-adaptive decisions at the national forest level. In the absence of personal pro-adaptation attitudes and given the fact of missing institutional incentives, unfunded mandates like the climate scorecard may have the unintended outcome of de-motivating engagement given latent mistrust in perceived fickle mandates. At the same time, initiatives like the scorecard can be seen as a significant first step towards fostering more extensive transformation within the USFS, and in advance of budget-driven initiatives should they come to be implemented.

The roles of history and experience have the potential to influence engagement with adaptation in yet another way. Scholars working at the intersection of human behaviour and risk perception often point to the importance of a critical experience that ultimately triggers action (Spence et al., 2011). Whether it is a flood (as anticipated by one the respondents) or some other triggering event, such experiences have the potential to accelerate engagement and policy action within the context of ongoing incremental changes (Repetto, 2006).

Lastly, considering anticipated pathways forward for adaptation within the USFS, the views of managers presented in this study are consistent with those of many adaptation scholars and practitioners alike who similarly emphasize that adaptation objectives should be incorporated alongside policy and planning across domains (e.g. not kept in a climate change silo). This, "mainstreaming" of climate is generally viewed as preferable to stand alone climate policies for institutional adaptation (Berrang-Ford et al., 2011; Smit and Wandel, 2006). Specific insights from interviewees point to the importance of incorporating climate objectives into institutional budget targets, rather than seeking to advance unfunded mandates and programs. As above, 
doing so has the potential not only to motivate action, but also to engender trust in the stability of the mandate.

\section{Conclusions: implications for research and adaptation implementation}

The study presented here provides a novel contribution to the evolving literature about adaptation barriers. Although often overlooked by climate adaptation specialists, this study demonstrates the prominent and interrelated roles of nonmaterial factors including attitudes, experience and trust. Perhaps the most salient observations and associated conclusions to be drawn from this material is to highlight the asymmetry in terms of the relative attention paid to nonmaterial barriers in the field of adaptation barriers and their observed influence (and perhaps even the relative ease with which they can be addressed). Empirical, case based and longitudinal research into the relative roles of nonmaterial and material barriers at different points in the adaptation process provide a promising avenue for future research in the service of both advancing the field of adaptation barriers and providing insights for developing robust, effective and behavioral realistic adaptation responses in practice

Lastly, this study raises at least four interrelated questions for policy communities concerned with adaptation. First, the observations related to capacity add weight to existing concerns about the adequacy of resources needed to respond to adaptation - in terms of human resources, time and funding. How might organizations such as the USFS better support managers in their effort to respond to climate change? Second, given that the provision of technical information is not seen as a major barrier for managers, how might budget commitments and related decisions be modified to more effectively support nascent adaptation initiatives? For example, by supporting the co-production of knowledge and by providing decision support that addresses expressed information needs where they have been identified (e.g. questions relating to culverts, road conditions and erosion risks). Third, how might institutional commitments and targets be modified to incentivize and operationalize pro-adaptation actions that would respond to changing conditions on the landscape? Fourth, how might agencies better recognize that engagement with climate adaptation may be rejected for deeply rooted - trust or attitude based reasons, and what might be done to address this? Answering these and other questions will require the combined 
efforts of social scientists, climate adaptation specialists, and practitioners working to advance analytical and applied understanding of adaptation as it is pursued in specific natural resource systems.

\section{Acknowledgments}

The author gratefully acknowledges the participation of the 25 managers and specialists and across Region 6 for giving their time in interviews and follow-up conversations, and for providing their perspectives. This research would not have been possible without their participation and I sincerely hope that I have done justice to their views in this paper. The interviews presented here were conducted as part of a related applied research project (separate results forthcoming) funded by the USDA-USFS Pacific Northwest Research Station and in collaboration with the Climate Impacts Group, University of Washington. The author also wishes to thank Dr. Amy Snover for valuable comments at the development stage of this work as well as the suggestions of two anonymous reviewers. 


\section{References}

Adger, W.N., 2014. Social Capital , Collective Action , and Adaptation to Climate Change 79, $387-404$.

Adger, W.N., Lorenzoni, I., O’Brien, K., 2009. Adaptation now, in: Adger, W.N., Lorenzoni, I., O’Brien, K. (Eds.), Adapting to Climate Change: Thresholds, Values, Governance. Cambridge University Press, Cambridge, UK, pp. 1-22.

Agrawal, A., 2010. Local Institutions and Adaptation to Climate Change, in: Mearns, R., Norton, A. (Eds.), Social Dimensions of Climate Change: Equity and Vulnerability in a Warming World. The International Bank for Reconstruction and Development / The Word Bank.

Archie, K.M., Dilling, L., Milford, J.B., Pampel, F.C., 2014. Unpacking the "information barrier": Comparing perspectives on information as a barrier to climate change adaptation in the interior mountain West. J. Environ. Manage. 133, 397-410. doi:10.1016/j.jenvman.2013.12.015

Archie, K.M., Dilling, L., Milford, J.B., Pampel, F.C., 2012. Climate change and western public lands: A Survey of U.S. Federal land managers on the status of adaptation efforts. Ecol. Soc. 17. doi:10.5751/ES-05187-170420

Berkhout, F., 2012. Adaptation to climate change by organizations. Wiley Interdiscip. Rev. Clim. Chang. 3, 91-106. doi:10.1002/wcc.154

Berrang-Ford, L., Ford, J.D., Paterson, J., 2011. Are we adapting to climate change? Glob. Environ. Chang. 21, 25-33. doi:10.1016/j.gloenvcha.2010.09.012

Bierbaum, R., Smith, J.B., Lee, A., Blair, M., Carter, L., Chapin, F.S., Fleming, P., Ruffo, S., Stults, M., McNeeley, S., Wasley, E., Verduzco, L., 2013. A comprehensive review of climate adaptation in the United States: More than before, but less than needed. Mitig. Adapt. Strateg. Glob. Chang. 18, 361-406. doi:10.1007/s11027-012-9423-1

Biesbroek, G.R., Klostermann, J.E.M., Termeer, C.J. a M., Kabat, P., 2013. On the nature of barriers to climate change adaptation. Reg. Environ. Chang. 13, 1119-1129. doi:10.1007/s10113-013-0421-y

Castree, N., Adams, W.M., Barry, J., Brockington, D., Büscher, B., Corbera, E., Demeritt, D., Duffy, R., Felt, U., Neves, K., Newell, P., Pellizzoni, L., Rigby, K., Robbins, P., Robin, L., Rose, D.B., Ross, A., Schlosberg, D., Sörlin, S., West, P., Whitehead, M., Wynne, B., 2014. Changing the intellectual climate. Nat. Clim. Chang. 4, 763-768. doi:10.1038/nclimate2339

Charmaz, K., 2006. Constructing Grounded Theory: A Practical Guide Through Qualitative Analysis. SAGE Publications, Thousand Oaks, California. 
Creswell, J.W., 2013. Qualitative Inquiry and Research Design: Choosing Among Five Approaches. SAGE Publications, Thousand Oaks, California.

Eisenack, K., Moser, S.C., Hoffmann, E., Klein, R.J.T., Oberlack, C., Pechan, A., Rotter, M., Termeer, C.J. a. M., 2014. Explaining and overcoming barriers to climate change adaptation. Nat. Clim. Chang. 4, 867-872. doi:10.1038/nclimate2350

Ekstrom, J., Moser, S.C., 2013. Institutions as key element to successful climate adaptation processes: Results from the San Francisco Bay Area, in: Moser, S.C., Boykoff, M. (Eds.), Successful Adaptation to Climate Change: Linking Science and Policy in a Rapidly Changing World. Routledge, Abingdon, Oxon, pp. 97-113.

Emerson, R.., Fretz, R., Shaw, L., 1995. Writing Ethnographic Fieldnotes. University of Chicago Press, Chicago.

Folke, C., Hahn, T., Olsson, P., Norberg, J., 2005. Adaptive Governance of Social-Ecological Systems. Annu. Rev. Environ. Resour. 30, 441-473. doi:10.1146/annurev.energy.30.050504.144511

Furniss, M., Roby, K., Cenderelli, D., Chatel, J., Clifton, C.F., Clingenpeel, A., Hays, P., Higgins, D., Hodges, K., Howe, C., Jungst, L., Louie, J., Mai, C., Martinez, R., Overton, K., Staab, B., Steinke, R., Weinhold, M., 2013. Assessing the Vulnerability of Watersheds to Climate Change, Gen. Tech. Report. PNW-GTR-884. Portland, Oregon.

Grothmann, T., Patt, A., 2005. Adaptive capacity and human cognition: The process of individual adaptation to climate change. Glob. Environ. Chang. 15, 199-213. doi:10.1016/j.gloenvcha.2005.01.002

Hagerman, S.M., Satterfield, T., 2013. Entangled judgments: Expert preferences for adapting biodiversity conservation to climate change. J. Environ. Manage. 129, 555-563. doi:10.1016/j.jenvman.2013.07.033

Halofsky, J., Peterson, D.L., O’Halloran, K., Hawkins Hoffman, C., 2011. Adapting to Climate Change at Olympic National Forest and Olympic National Park, General Technical Report, PNW-GTR-844. U.S. Department of Agriculture, Forest Service, Portland, Oregon.

Holstein, J.A., Gubrium, J.F., 1995. The Active Interview. SAGE Publications, Thousand Oaks, California.

IPCC, 2014. CLIMATE CHANGE 2014 Synthesis Report Summary for Policymakers, in: Team, T.C.W., Pachauri, R., Meyer, L. (Eds.), . Intergovernmental Panel on Climate Change.

Jantarasami, L.C., Lawler, J.J., Thomas, C.W., 2010. Institutional Barriers to Climate Change Adaptation in U . S . National Parks and Forests. Ecol. Soc. 15, 33. doi:33 
Jasanoff, S., 2004. Ordering Knowledge, Ordering Society, in: States of Knowledge. The CoProduction of Science and Social Order. Routledge, New York, pp. 13-45. doi:10.4324/9780203413845

Kahneman, D., 2011. Thinking fast and slow. Doubleday Canada.

Lemos, M.C., Agrawal, A., 2006. Environmental Governance. Annu. Rev. Environ. Resour. 31, 297-325. doi:10.1146/annurev.energy.31.042605.135621

Matthews, R., Sydneysmith, R., 2010. Climate Change and Institutional Capacity in an "Arctic Gateway" City: A CAVIAR Case Study of Whitehorse, in: Hovelsrud, G.K., Smit, B. (Eds.), Community Adaptation and Vulnerability in Arctic Regions. Springer Science+Business Media, pp. 239-261.

Maxwell, J.A., 2013. Qualitative Research Design: An Interactive Approach. SAGE Publications, Thousand Oaks, California.

Millar, C.I., Stephenson, N.L., Stephens, S.L., 2007. CLIMATE CHANGE AND FORESTS OF THE FUTURE : mm. Ecol. Appl. 17, 2145-2151. doi:10.1890/06-1715.1

Moran, E. 2006. People and Nature: An introduction to human ecological relations. Blackwell Publishing, Malden MA, USA.

Moser, S.C., Boykoff, M., 2013. Climate change adaptation success: the scope of the challenge, in: Moser, S.C., Boykoff, M. (Eds.), Successful Adaptation to Climate Change: Linking Science and Policy in a Rapidly Changing World. Routledge, Abingdon, Oxon, pp. 1-33.

Moser, S.C., Ekstrom, J. a, 2010. A framework to diagnose barriers to climate change adaptation. Proc. Natl. Acad. Sci. U. S. A. 107, 22026-22031. doi:10.1073/pnas.1007887107

Ogden, A.E., Innes, J.L., 2009. Application of structured decision making to an assessment of climate change vulnerabilities and adaptation options for sustainable forest management. Ecol. Soc. 14. doi:Artn 11

Pelling, M., High, C., Dearing, J., Smith, D., 2008. Shadow spaces for social learning: A relational understanding of adaptive capacity to climate change within organisations. Environ. Plan. A 40, 867-884. doi:10.1068/a39148

Peterson, D.L.., Millar, C.I.., Joyce, L.A.., Furniss, M.J.., Halofsky, J.E.., Neilson, R.P.., Morelli, T.L.., 2011. Responding to climate change in national forests: A guidebook for developing adaptation options. USDA For. Serv. - Gen. Tech. Rep. PNW-GTR 1-99.

Repetto, R., 2006. Punctuated equilibrium and the dynamics of US environmental policy. Yale University Press, New Haven. 
Saldana, J., 2013. The Coding Manual for Qualitative Researchers. SAGE Publications, Thousand Oaks, California.

Smit, B., Wandel, J., 2006. Adaptation, adaptive capacity and vulnerability. Glob. Environ. Chang. 16, 282-292. doi:10.1016/j.gloenvcha.2006.03.008

Spence, a., Poortinga, W., Butler, C., Pidgeon, N.F., 2011. Perceptions of climate change and willingness to save energy related to flood experience [Letter]. Nat. Clim. Chang. 1, 46-49. doi:10.1038/nclimate1059

Staudt, A., Leidner, A.K., Howard, J., Brauman, K. a., Dukes, J.S., Hansen, L.J., Paukert, C., Sabo, J., Solórzano, L. a., 2013. The added complications of climate change: Understanding and managing biodiversity and ecosystems. Front. Ecol. Environ. 11, 494-501. doi:10.1890/120275

Suckall, N., Tompkins, E., Stringer, L., 2014. Identifying trade-offs between adaptation, mitigation and development in community responses to climate and socio-economic stresses: Evidence from Zanzibar, Tanzania. Appl. Geogr. 46, 111-121. doi:10.1016/j.apgeog.2013.11.005

Tribbia, J., Moser, S.C., 2008. More than information: what coastal managers need to plan for climate change. Environ. Sci. Policy 11, 315-328. doi:10.1016/j.envsci.2008.01.003

USDA, 2015. Department of Agriculture Regional Climate Hubs Strategic Plan.

USDA, 2014. US Department of Agriculture Climate Change Adaptation Plan.

USDA, 2010. Strategic Plan FY 2010-2015 50. doi:10.1037/e583052010-001

USFS, 2014. Engaging a Climate Ready Agency. Newsl. Clim. Chang. Advis. Off. October 31, $1-10$.

USFS-USDA, 2012. Land Areas of the National Forest System, FS-383.

USFS-USDA, 2011. Navigating the Climate Change Performance Scorecard: A Guide for National Forests and Grasslands (Version 2).

USFS-USDA, 2010. National Roadmap for Responding to Climate Change.

USFS-USDA, 2008. Forest Service Strategic Framework for Responding to Climate Change.

Vose, J., Peterson, D.L., Patel-Weynand, T., 2012. Effectis of climatic variability and change on forest ecosystems: a comprehensive science synthesis for the US forest sector., Gen. Tech. Rep. PNW-GTR-870. Portland, Oregon. 
Yin, R.K., 2003. Applications of case study research. SAGE Publications, Thousand Oaks, California. 
Appendix A. Types of questions explored during interviews with managers and specialists in the Pacific Northwest Region of the USFS.

\section{Sample interview questions}

Can you tell me about your current position, and your involvement with any climate-related initiatives/projects/programs?

What are the most pressing management issues that you face in your job today?

What do you foresee as being the most pressing issues on this forest in the next 15-25 years?

What factors influence your ability to carry out your work? In general or relating to climate change adaptation?

Is your unit implementing or considering implementing any climate-specific adaptation actions or strategies?

(If yes) What is the nature/approach of these actions? What shapes your ability to implement adaptation initiatives and actions on your forest?

What is needed to facilitate successful adaptation implementation?

How important is it for you personally to address climate change in your day-to-day management?

Overall, how would you describe the approach of your unit with respect to how important or not addressing climate change is currently in day-to-day operations?

What types of information would be useful to support adaptation on your forest?

Is there anything we haven't discussed that you would like to mention? 